\title{
Ethnic Variation in Blood Pressure among Preadolescent Children
}

\author{
TOM BARANOWSKI, YI TSONG, ${ }^{1}$ JANICE HENSKE, J. KAY DUNN, ${ }^{2}$ AND PAUL HOOKS \\ Department of Preventive Medicine and Community Health, University of Texas Medical Branch, \\ Galveston, Texas 77550
}

\begin{abstract}
As part of a study on methods for assessing diet and exercise among 163 3rd to 6th grade students, data were collected on blood pressure, diet, urinary electrolytes, aerobic activity, resting pulse, and body composition. Data were collected on a stratified sample, with almost equal numbers of children of both sexes from 3rd or 4th and 5th or 6th grades; from three ethnicities: Anglo-, Black- and Mexican-American. Three resting blood pressures were obtained using a Hawksley random zero sphygmomanometer. Data analytic procedures relied on analyses of variance and covariance to assess differences across design factors in blood pressure, with dietary sodium, resting pulse, body surface area, and energy expended as covariates. No differences were detected across ethnic groups in systolic pressures, but Mexican-American children were shown to have significantly higher diastolic fourth phase pressures than Anglo- or Black-American children. Only the dietary variables differed across ethnic groups, but not in the same pattern. Differences in the covariates did not account for the difference across ethnic groups in diastolic pressures. (Pediatr Res 23: 270-274, 1988)
\end{abstract}

\section{Abbreviations}

MET, metabolic equivalent units

BSA, body surface area

HDFP, hypertension detection and follow-up program

MRFIT, multiple risk factor intervention trial

CDC, centers for disease control

NCC, nutrition coordinating center

NHLBI, national heart, lung, and blood institute

ANOVA, analysis of variance

ANCOVA, analysis of covariance

SBP, systolic blood pressure

DBP, diastolic blood pressure investigators have shown that the blood pressure values among adults are related to dietary variables (2-5) and others to exercise or aerobic activity $(6,7)$. Attempting to explain Black-White differences, two groups of investigators have shown that while Black-American adults did not consume more sodium than White-Americans, they consumed less potassium $(2,3)$. This higher potassium consumption might serve to decrease the Anglo-American blood pressures relative to Black-Americans.

Comparisons of blood pressure values across ethnic groups among children are conflicting. In some studies Black-American children had higher blood pressure values than White-American children (8). Others have found the reverse or mixed patterns varying by age $(3,9)$; some found no differences $(10,11)$; one found higher values among Black children in one community, but not in another (12). Several studies compared children across three ethnicities $(8,9,13,14)$. Two studies showed MexicanAmerican children's blood pressures did not differ from those of Anglo-Americans, and both were lower than those of BlackAmericans $(8,13)$. The other two studies showed complex differences among ethnicity, age, and gender groups separately for systolic and diastolic pressures $(9,14)$.

Several studies attempted to explain the obtained ethnic group differences in children's blood pressures $(10,15-18)$. One consistent finding has been the importance of body size in predicting blood pressures, whether body size was measured by height or by body mass indices $(3,12,16,19,20)$. None has examined the relative influence of diet and habitual physical activity in accounting for ethnic group differences among children, although physical activity has been related to blood pressure among children (21). In light of these results, we attempted to answer three questions: Do preadolescent child blood pressures differ across three ethnic groups? Do commonly considered risk factors or correlates of blood pressure, e.g. diet, exercise, or body size variables, differ across these ethnic groups? Do obtained differences in risk factors or correlates account for the differences in blood pressure?

\section{METHODS}

Blood pressure levels have been documented to be higher among Black-American than White-American adults (1). Some

Received August 6, 1986; accepted October 29, 1987

Correspondence and reprint requests Tom Baranowski, Ph.D., UTMB, Preventive Medicine and Community Health, J-25, Shearn Moody Plaza, Suite 7020, Galveston, TX 77550-2782.

Supported by grants from the National Heart, Lung, and Blood Institute and the Moody Foundation. A preliminary version of these findings was presented at the National Conference on High Blood Pressure Control, Chicago, 1985, and at the annual meeting of the Association for the Advancement of Health, Physical Education, Recreation and Dance, 1986.

${ }^{1}$ Present address Division of Biostatistics, HFN-715, Center of Drugs and Biologics, Food and Drug Administration, Rockville, MD.

${ }^{2}$ Present address Design and Analysis Core, DeBakey Heart Center Baylor College of Medicine, Houston, TX.
Design. Data were collected as part of a methodologic study on techniques for enabling children to accurately self-report diet and exercise habits. This study was designed to be balanced for ethnicity, i.e. equal numbers of Anglo-, Black- and MexicanAmerican children; gender, i.e. equal numbers of boys and girls; and grade level, i.e. equal numbers of 3 rd or 4th and 5th or 6th graders. Ethnic classification excluded those born outside of the United States and those of Hispanic origin other than Mexico.

Procedures. Procedures for recruiting participants have been reported elsewhere $(22,23)$. Of the 200 families approached 186 $(93 \%)$ agreed to participate. The percents were 86,92 , and 100 for Mexican-American, Black-American, and Anglo-American, respectively. The major reason for low participation among Mexican-Americans was lack of fluency in English, which was a 
limitation for our staff. As per Institutional Review Board approval, child informed assent and parental informed consent were obtained at the time of recruitment. Participation involved a 1-wk commitment from the child and family. On the late Friday afternoon before participation, two staff members went to the home and trained the child and parent in collection of overnight urine samples and in diet and exercise form completion. Urine values were collected for each of 6 nights, beginning with Sunday night and ending the next Friday night.

On the Friday morning after the start of data collection, the child came to clinic, brought five of six urine samples, and participated in the following: resting heart rate, resting blood pressure, height and weight, 24-h diet recall, 2-wk summative frequency of consumption report, and a 7-day exercise recall. The sixth urine sample was picked up by staff the next morning. The child received a project $T$-shirt at the initial session and 20 dollars at the end of the clinic session.

Measures. Resting Pulse and Blood Pressure. A resting pulse and three blood pressures were collected on the right arm after 5 min of quiet sitting rest, using the guidelines of the American Heart Association (24) and the protocol of the HDFP study (25). A random zero sphygmomanometer was used, with at least a 30 $s$ wait between each of the three assessments. The average of the three values of the first (systolic) and fourth (diastolic) Korotkoff sounds were used as the major dependent variables. All staff measuring blood pressures met the accuracy criteria of the HDFP videotape and protocol, including fourth phase pressures. As a quality control procedure, blood pressures were independently assessed by two staff members at periodic intervals across the conduct of this study. No significant sources of error were detected in this manner; no evidence of terminal digit preference was detected.

Height and Weight. The MRFIT protocol for height and weight assessment was used. A CDC anthropometer was used for height and a Detecto (c) balance beam scale was used for weight. BSA (26), which corrects weight for height $\left(\mathrm{kg} / \mathrm{m}^{2}\right)$, was used in the analyses.

Twenty-Four-H Diet Recall. All children were interviewed by registered dietitians, who were trained and certified by the NCC of the University of Minnesota in standard NHLBI dietary interviewing techniques (27). Data were recorded on specially designed NCC forms and sent to the NCC for standardized nutrient quantification. Daily kcal consumption was used as a correction value in the analyses.

Frequency of Dietary Consumption. Special forms were used enabling children to report their frequency of consumption of foods within selected nutrient homogenous food categories using a daily diary format. This form was modified from our previous research, includes frequencies for each of 7 days of consumption, and has been demonstrated to provide valid estimates (28). An average daily nutrient intake estimate was obtained by using standard texts for nutrient density $(29,30)$ multiplied by average portion sizes (31), multiplied by frequencies from the form, and divided by the number of days recorded.

Seven-Day Exercise Recall. Trained interviewers collected selfreport information on the school and nonschool activities of children for the 7 days before the day of interview. The Stanford protocol (32) was modified to obtain estimates of activity performed for each of the previous 7 days which were averaged. An average daily total energy expended in MET was calculated using the Stanford procedures (32).

Urine Samples. The Liu-Stamler protocol for collecting overnight urine samples (33) was rewritten to be understood by children and parents. Participants and parents were trained in all procedures and in the accurate recording of time and date. The IL Flame Photometer was used for determination of urinary sodium and potassium values. A Beckman creatinine analyzer using the kinetic alkaline picrate method was used for creatinine determinations. Sodium and potassium values were standardized to estimate excretion during an 8 -h overnight time period.
Data analyses. Systolic and diastolic (4th phase) blood pressures were subjected to ANOVA with three fixed factors: ethnicity (Anglo-, Black-, and Mexican-American), gender (male, female), and grade (3rd or 4th grades, 5th or 6th grades). Duncan's multiple range test was applied when necessary to compare the means between pairs of the three ethnic groups (34). In order to examine if differences across ethnic or gender groups in risk factors or correlates obscured or contributed to the differences across ethnic or gender groups in blood pressures, ANCOVA were used, using a 2-way (ethnicity and gender) ANOVA model, with the proposed explanatory variables as covariates. The reported zero-order or partial correlations were all Pearson product-moment correlation coefficients. A $p$ value of $<0.05$ was considered statistically significant. Because of the large number of tests, consistent patterns in findings were sought rather than isolated significant results.

\section{RESULTS}

Sample description. Complete data were obtained on 163 children and thereby constituted the sample for these analyses. The distribution of these cases according to gender, grade, and ethnicity groups is given in Table 1. Data on 36 cases were discarded from the original sample of 199 for the following reasons: 26 cases with insufficient urine collection (less than 4 days), four cases with incomplete summative diet data, and two cases with no 7-day exercise recall data.

ANOVA analyses. Differences across Gender Groups in Blood Pressure. Sample means and SD of systolic and diastolic blood pressures are displayed within design subgroups in Table 2. ANOVA revealed no statistically significant differences across any design factors in SBP. Significant main effects for ethnicity and gender $(p<0.01)$ were obtained in DBP. A Duncan's multiple range test revealed significantly $(p<0.01)$ higher diastolic pressures for Mexican-American over Anglo- and BlackAmericans, with no significant differences between the latter.

Differences across Groups in Covariates. Regarding the risk factors and correlates, ANOVA procedures revealed significant differences among ethnicities in dietary sodium consumption $(p$ $<0.02$ ) with Black-Americans consuming higher quantities than Anglo-Americans; in dietary potassium consumption $(p<0.03)$ with Anglo-Americans consuming lower quantities than Blackor Mexican-Americans; in the ratio of dietary sodium to potassium $(p<0.05)$ with Black-Americans having higher ratios than Anglo- and Mexican-Americans; and in overnight urinary sodium measures $(p<0.01)$ with Black-Americans having higher measures than Anglo- and Mexican-Americans. Significant differences were revealed between genders in resting pulse $(p<$

Table 1. Sample size by cells of 163 cases used for analysis in design of Family Health Project IV

\begin{tabular}{cccccc}
\hline & & \multicolumn{5}{c}{ Ethnicity } \\
\cline { 3 - 6 } Gender & Grades & $\begin{array}{c}\text { Anglo- } \\
\text { American }\end{array}$ & $\begin{array}{c}\text { Black- } \\
\text { American }\end{array}$ & $\begin{array}{c}\text { Mexican- } \\
\text { American }\end{array}$ & Totals \\
\hline Male & $3-4$ & 13 & 13 & 15 & 41 \\
& $5-6$ & 13 & 15 & 15 & 43 \\
Female & $3-4$ & 14 & 12 & 11 & 37 \\
& $5-6$ & 17 & 14 & 11 & 42 \\
Grade & $3-4$ & 27 & 25 & 26 & 78 \\
alone & $5-6$ & 30 & 29 & 26 & 85 \\
Gender & $\mathrm{M}$ & 26 & 28 & 30 & 84 \\
alone & $\mathrm{F}$ & 31 & 26 & 22 & 79 \\
& & & & & \\
Totals & & 57 & 54 & 52 & 163 \\
\hline
\end{tabular}


0.05 ) with boys having lower resting pulse rates, and in energy expenditure $(p<0.005)$ with girls having lower means. Significant differences between grades were revealed in BSA $(p<0.001)$ with higher grades having higher values, as would be expected. Significant gender by grade interactions were revealed in urinary potassium and ratio of sodium to potassium with higher values in lower grades in boys and vice versa in girls. The means and $\mathrm{SD}$ of some of these variables are given by ethnic and gender groups in Table 3.

ANCOVA analyses. Dietary sodium consumption, resting pulse rate, energy expenditure, and BSA were selected as the covariates in ANCOVA for SBP and DBP due to one of the following reasons: 1) high zero order correlation with blood pressures; 2) significantly different mean values among ethnicities or between genders, or 3) among the first four independent variables selected through the maximum $R$ method in multiple regression analyses of blood pressures. Due to the high correlations among dietary consumption and urinary electrolyte measures, only dietary sodium consumption was used in the ANCOVA.

Unicovariate analyses of $S B P$. In the unicovariate analyses of SBP, there was no statistical evidence to reject the assumption of homogeneity of slopes of dietary sodium consumption, resting pulse, or energy expenditure. There were no significant differences among ethnicities or between genders in SBP when data were adjusted for each of dietary sodium consumption or energy expenditure in turn (see Table 4). However, a moderately significant difference between genders was detected $(p=0.05)$ with boys having higher SBP than girls when adjusted for resting pulse.

When BSA was used as a single covariate, the SBP versus BSA

Table 2. Mean and (SD) of SBP and DBP (4th phase) in $\mathrm{mm} \mathrm{Hg}$

\begin{tabular}{clcccc}
\hline & & & \multicolumn{3}{c}{ Ethnicity } \\
\cline { 3 - 6 } Pressure & Gender & Grade & $\begin{array}{c}\text { Anglo- } \\
\text { American }\end{array}$ & $\begin{array}{c}\text { Black- } \\
\text { American }\end{array}$ & $\begin{array}{c}\text { Mexican- } \\
\text { American }\end{array}$ \\
\hline SBP & Male & $3-4$ & $98.8(8.2)$ & $94.8(9.4)$ & $97.6(8.9)$ \\
& & $5-6$ & $96.7(6.8)$ & $102.8(13.2)$ & $98.8(5.9)$ \\
& Female & $3-4$ & $94.9(9.8)$ & $97.3(7.4)$ & $96.0(4.6)$ \\
& & $5-6$ & $95.6(7.9)$ & $97.7(8.1)$ & $95.8(8.0)$ \\
DBP & \multirow{2}{*}{ Male } & $3-4$ & $53.5(10.5)$ & $54.8(9.6)$ & $61.0(8.9)$ \\
& & $5-6$ & $56.1(12.0)$ & $58.9(10.1)$ & $64.4(9.3)$ \\
& Female & $3-4$ & $60.9(7.7)$ & $60.7(8.6)$ & $67.3(7.4)$ \\
& & $5-6$ & $61.3(5.4)$ & $63.7(8.2)$ & $63.4(6.1)$ \\
\hline
\end{tabular}

slopes were significantly different among ethnic and gender groups. Thus, it is inappropriate to use usual analysis of covariance techniques with body surface area as a covariate. When two-way ANOVA was applied with SBP adjusted to the mean value of $\mathrm{BSA}$, it revealed a moderately significant difference between genders $(p=0.06)$ with boys having higher SBP, while controlling for an ethnicity effect.

Multicovariate analysis of SBP. Heterogeneity of slopes existed in BSA and energy expenditure when all covariates were entered into the ANCOVA model simultaneously. Similar magnitudes of boy-girl difference were revealed when SBP was adjusted by covariates, and analysis of variance was used at the mean values of each covariate $(p=0.04)$.

Uni- and multicovariate analyses of $D B P$. In the analyses of covariance of DBP, the assumption of homogeneity of slopes was established for each and for the combination of all four covariates. Classical ANCOVA revealed that only BSA was significantly related to DBP and correcting for these covariates separately and together did not change the statistical significance of the differences among ethnicities or between genders, nor the patterns of differences across ethnic and gender groups. The mean values of SBP and DBP for each ethnic group, unadjusted and adjusted for each covariate, and the combination of covariates are in Table 4.

Table 4. Means and SEM of SBP and DBP adjusted by covariates

\begin{tabular}{lccc}
\hline & \multicolumn{3}{c}{ Ethnicity } \\
\cline { 2 - 4 } & $\begin{array}{c}\text { Anglo- } \\
\text { American }\end{array}$ & $\begin{array}{c}\text { Black- } \\
\text { American }\end{array}$ & $\begin{array}{c}\text { Mexican- } \\
\text { American }\end{array}$ \\
\hline SBP & & & \\
$\quad$ Unadjusted & $96.42 \pm 1.08$ & $98.33 \pm 1.38$ & $97.23 \pm 0.97$ \\
Adjusted by & & & \\
$\quad$ Sodium & $96.18 \pm 1.16$ & $98.64 \pm 1.18$ & $97.07 \pm 1.20$ \\
$\quad$ Resting pulse & $96.22 \pm 1.14$ & $98.50 \pm 1.16$ & $97.10 \pm 1.20$ \\
$\quad$ Energy expenditure & $96.48 \pm 1.14$ & $98.34 \pm 1.17$ & $97.10 \pm 1.20$ \\
$\quad$ BSA & $96.63 \pm 0.97$ & $97.36 \pm 1.00$ & $97.89 \pm 1.03$ \\
$\quad$ Multiple covariates & $96.10 \pm 0.93$ & $97.85 \pm 0.96$ & $97.60 \pm 0.97$ \\
& & & \\
DBP & & & \\
Unadjusted & $58.23 \pm 1.24$ & $59.54 \pm 1.29$ & $63.83 \pm 1.15$ \\
Adjusted by & & & \\
$\quad$ Sodium & $57.73 \pm 1.19$ & $59.86 \pm 1.22$ & $64.05 \pm 1.23$ \\
$\quad$ Resting pulse & $57.87 \pm 1.18$ & $59.20 \pm 1.20$ & $64.07 \pm 1.24$ \\
$\quad$ Energy expenditure & $57.95 \pm 1.17$ & $59.64 \pm 1.20$ & $64.04 \pm 1.24$ \\
$\quad$ BSA & $58.00 \pm 1.15$ & $59.25 \pm 1.18$ & $64.38 \pm 1.22$ \\
\hline
\end{tabular}

Table 3. Sample means and (SD) of hypertension risk factors and correlates within ethnicity and gender groups

\begin{tabular}{|c|c|c|c|c|c|c|}
\hline & \multicolumn{2}{|c|}{ Anglo-American } & \multicolumn{2}{|c|}{ Black-American } & \multicolumn{2}{|c|}{ Mexican-American } \\
\hline & Boy & Girl & Boy & Girl & Boy & Girl \\
\hline Resting pulse* (beats/min) & $\begin{array}{l}77.5 \\
(8.7)\end{array}$ & $\begin{array}{l}83.5 \\
(6.2)\end{array}$ & $\begin{array}{l}75.5 \\
(6.7)\end{array}$ & $\begin{array}{l}78.8 \\
(9.9)\end{array}$ & $\begin{array}{l}76.1 \\
(9.1)\end{array}$ & $\begin{array}{l}79.0 \\
(8.2)\end{array}$ \\
\hline Dietary sodium $\dagger(\mathrm{mg})$ & $\begin{array}{c}3055 \\
(1764)\end{array}$ & $\begin{array}{c}3464 \\
(1629)\end{array}$ & $\begin{array}{c}4272 \\
(1921)\end{array}$ & $\begin{array}{c}4739 \\
(1888)\end{array}$ & $\begin{array}{c}4156 \\
(2206)\end{array}$ & $\begin{array}{c}3701 \\
(2056)\end{array}$ \\
\hline Dietary potassium $\dagger(\mathrm{mg})$ & $\begin{array}{c}2383 \\
(1239)\end{array}$ & $\begin{array}{c}2425 \\
(1080)\end{array}$ & $\begin{array}{c}3124 \\
(1723)\end{array}$ & $\begin{array}{c}3109 \\
(1531)\end{array}$ & $\begin{array}{c}3110 \\
(1680)\end{array}$ & $\begin{array}{c}2802 \\
(1298)\end{array}$ \\
\hline Dietary $\mathrm{Na} / \mathrm{K} \dagger$ (ratio) & $\begin{array}{c}1.29 \\
(0.49)\end{array}$ & $\begin{array}{c}1.47 \\
(0.53)\end{array}$ & $\begin{array}{c}1.57 \\
(0.61)\end{array}$ & $\begin{array}{c}1.69 \\
(0.65)\end{array}$ & $\begin{array}{c}1.43 \\
(0.46)\end{array}$ & $\begin{array}{r}1.40 \\
(0.57)\end{array}$ \\
\hline $\begin{array}{l}\text { Urinary sodium } \dagger \text { ( } 8 \text {-h excre- } \\
\text { tion in } \mathrm{mEq} \text { ) }\end{array}$ & $\begin{array}{l}27.2 \\
(7.7)\end{array}$ & $\begin{array}{c}26.6 \\
(11.1)^{\circ}\end{array}$ & $\begin{array}{c}33.8 \\
(11.8)\end{array}$ & $\begin{array}{c}34.5 \\
(17.7)\end{array}$ & $\begin{array}{c}26.2 \\
(12.2)\end{array}$ & $\begin{array}{c}30.0 \\
(12.1)\end{array}$ \\
\hline $\mathrm{BSA}\left(\mathrm{kg} / \mathrm{m}^{2}\right)$ & $\begin{array}{c}1.24 \\
(0.17)\end{array}$ & $\begin{array}{c}1.21 \\
(0.18)\end{array}$ & $\begin{array}{c}1.26 \\
(0.22)\end{array}$ & $\begin{array}{c}1.29 \\
(0.22)\end{array}$ & $\begin{array}{c}1.20 \\
(0.17)\end{array}$ & $\begin{array}{c}1.19 \\
(0.20)\end{array}$ \\
\hline Energy expenditure* (MET) & $\begin{array}{l}37.1 \\
(4.2)\end{array}$ & $\begin{array}{l}35.3 \\
(2.8)\end{array}$ & $\begin{array}{l}36.8 \\
(3.5)\end{array}$ & $\begin{array}{l}34.7 \\
(2.5)\end{array}$ & $\begin{array}{l}36.8 \\
(3.8)\end{array}$ & $\begin{array}{l}34.6 \\
(3.2)\end{array}$ \\
\hline
\end{tabular}

$* p<0.05$ for differences across gender group means.

$\dagger p<0.05$ for differences across ethnic group means. 
Analyses with correction factors. A series of zero order and partial correlations was calculated within ethnic and gender subgroups between the blood pressures and covariates, while correcting for the other covariates by partial correlations. No consistent patterns were detected in these analyses.

To correct for the possibility that sodium consumption was merely a proxy for the total amount of food consumed, i.e. that children who ate more food consumed more sodium, all the above analyses were repeated dividing the nutrient estimates by an estimate of total calories consumed. No refinements in results were detected when using this correction factor.

\section{DISCUSSION}

Significant differences in SBP were not detected across ethnic groups or for the ethnic-gender interaction. The literature is inconsistent on this point. Although Harris et al. (9) found that Hispanic boys had higher SBP than the Black- or Anglo-American boys, and Black-American girls' SBP were higher than those of the Anglo-American girls, Wheeler et al. (8) showed that Blacks had higher values than the other two groups. However, Levinson et al. (13) showed no differences across ethnic groups for girls, but Black boys were higher than White boys.

An ethnic group difference in diastolic fourth phase blood pressures was detected. Mexican-American children had higher values than the Anglo- or Black-American children, who were not different from each other. Alternatively, Harris et al (9), Wheeler et al. (8), and Levinson et al. (13) showed BlackAmerican boys and girls had the highest diastolic values, in comparison to Anglo- and Hispanic-Americans.

Berenson et al. (16) attempted to explain elevated blood pressure values separately in Black and Anglo groups. They reported that visual inspection of scatter plots of data indicated differential sodium sensitivity in children, i.e. they reported more highly elevated pressures in response to sodium consumption among hypertensives than among others. This relationship reportedly was stronger among Black-American children. In a follow-up study, Voors et al. (18) demonstrated higher correlations among Blacks than Whites in urinary sodium and potassium excretions and greater response of sodium balance and sodium excretion to a loss of potassium among Blacks than among Whites. The lack of higher blood pressures among Black-American children in the current study, despite the significantly higher consumption of sodium, does not support the notion of increased sodium sensitivity among segments of the Black-American population. The higher levels of potassium consumption among Blacks herein is in contrast to the findings with adult populations $(2,3)$. This may simply reflect regional variations in diet. The lack of significant relationship between blood pressure and dietary potassium, however, would not support the enhanced potassium effect on natriuresis as suggested by Voors et al. (18).

Szklo (35) reviewed the literature on differences in blood pressure between Black and White children. He concluded that local environmental factors most likely accounted for the differences as to which ethnic group had higher blood pressures, because biologically induced differences should be consistent across studies. Thus, the consistent Black-White differences in blood pressure, detectable among adults, are not detectable among children. The onset of puberty would not seem to account for subsequent differences either (36).

While Harlan et al. (4) demonstrated ethnic (Black-White) differences in SBP, they reported no attempt to explain those differences. Regression analyses within each gender-ethnic group revealed that skeletal age or height, and pulse rate were most consistently the important predictors of SBP; and pulse and skinfold thickness were most consistently the important predictors of DBP. Hohn et al. (10) reported that Blacks had higher excretions of sodium and lower excretions of potassium than among whites, but the pattern did not explain their pattern of blood pressure results. Although Hohn et al. (10) did not measure the amount of physical activity among these children, their exercise test of physical fitness did not differ across ethnic or parental hypertension groups, and so could not explain the differences.

The results of the current investigation are consistent with the latter two studies. A measure of body size was most clearly related to diastolic fourth phase blood pressure, but did not vary by ethnic group. Exercise values did not differ by ethnic group and it did not help explain patterns of blood pressure. The dietary variables, although varying by ethnicity, did not vary in a manner consistent with the blood pressure values and were not shown to be linearly related to DBP. Thus, diet, exercise, and body size could not explain the obtained differences across ethnic groups in DBP values in this study.

For some, the sample sizes in this study might be considered small. In ANOVA or ANCOVA, the power of the $F$ test is determined by the noncentrality of the F statistic, level of significance designated, the number of groups, and the number of observations. If we assume the sample noncentrality is the true population value, then the power of the $F$ test can be estimated using a power chart (35). For DBP in either a 3-way ANOVA or the various ANCOVA, the noncentrality of the F statistic was large, providing a power more than 0.95 (with $\alpha=0.05$ ) in all cases. This enabled us to detect differences of approximately 6 $\mathrm{mm} \mathrm{Hg}$ between Anglo- and Mexican-Americans and $4 \mathrm{~mm} \mathrm{Hg}$ between Black- and Mexican-Americans in DBP. For SBP, the noncentrality of the $\mathrm{F}$ statistic was almost zero in the 3-way ANOVA as well as the various ANCOVA, providing low power $(<0.10)$. This was due primarily to the small differences among means. The obtained differences in SBP of less than $2 \mathrm{~mm} \mathrm{Hg}$ across ethnicities are probably not sufficiently clinically significant to be of concern to detect.

Sample bias might also be of concern. Given, however, that $93 \%$ of contacted families agreed to participate, the participation rate is not a major concern. Although the participation rates varied across ethnicities, the lower rate $(86 \%)$ among MexicanAmericans was due to exclusions because of language difficulties. The potential for bias from the initial contact procedure, i.e. social networking $(22,23)$, cannot be estimated at this time. We know of no reason to believe that the procedure selectively eliminated candidates along lines related to genetic or environmental factors in blood pressure.

Given the findings in this study, in conjunction with the lack of consistently higher blood pressures among Mexican-American children reported in the literature, it is reasonable to assume that some unmeasured other environmental factors accounted for these differences, as suggested by Szklo (35), or interacted with genetic predispositions, which remain to be identified.

\section{REFERENCES}

1. Coleman AH, Ware DR, Long O 1980 Final Report of the National Black Health Providers Task Force on High Blood Pressure Education and Control NIH Publication No. 80-1474. National Heart Lung and Blood Institute, Washington, D.C.

2. Grim CE, Luft FC, Miller JZ, Meneely GR, Battarbee HD, Hames CG, Dah LK 1981 Racial differences in blood pressure in Evans County, Georgia: relationship to sodium a potassium intake and plasma renin activity. J Chronic Dis 33:87-98

3. Frisancho AR, Leonard WR, Bollettino LA 1984 Blood pressure in Blacks and whites and its relationship to dietary sodium and potassium intake. J Chronic Dis 37:515-519

4. Harlan WR, Cornoni-Huntlay J, Leaverton PE 1979 Blood pressure in childhood. The National Health Examination Survey. Hypertension 1:559-565

5. Langford HG 1983 Electrolyte intake and excretion and its correlation with blood pressure: studies in children and adults. In: R Gross, T Strasser (eds) Mild Hypertension: Recent Advances. Raven, New York, pp 177-218

6. Bjorntorp P 1982 Hypertension and exercise. Hypertension 4(suppl III):56-59

7. Blair SN, Goodyear NM, Gibbons LW, Cooper KH 1984 Physical fitness and incidence of hypertension in healthy normotensive men and women. JAMA 252:487-490

8. Wheeler RC, Marcus AC, Cullen JW, Konugres E 1983 Baseline chronic disease risk factors in racially heterogeneous elementary school population: the "know your body" program, Los Angeles. Prev Med 12:569-587

9. Harris RD, Phillips RL, Williams PM, Kuzma JW, Fraser GE 1981 The child- 
adolescent blood pressure study: I. Distribution of blood pressure levels in Seventh-Day Adventist (SDA) and Non-SDA children. Am J Public Health 71:1342-1349

10. Hohn AR, Riopel DA, Keil JE, Loadholt CB, Margolius HS, et al 1983 Childhood familial and racial differences in physiologic and biochemical factors related to hypertention. Hypertension 5:56-70

11. Schachter J, Kuller LH, Perfetti C 1984 Blood pressure during the first five years of life: relation to ethnic group (black or white) and to parental hypertension. Am J Epidemiol 119:541-553

12. Webber LS, Berenson GS 1985 Racial contrasts of blood pressure levels in two Southern rural communities. Prev Med 14:140-151

13. Levinson S, Liu K, Stamler J, Stamler R, Whipple I, Ausbrook D, Berkson D 1985 Ethnic differences in blood pressure and heart rate of Chicago schoolchildren. Am J Epidemiol 122:366-377

14. Gutgesell M, Terrell G, Labarthe D 1981 Pediatric blood pressure: Ethnic comparisons in a primary care center. Hypertension 3:39-46

15. Berenson GS, Voors AN, Dalferes ER, Webber LS, Shuller Se 1979 Creatine clearance, electrolytes, and plasma renin activity related to the blood pressure of white and black children-The Bogalusa Heart Study. J Lab Clin Med 93:535-548

16. Berenson GS, Voors AW, Webber LS, Dalferes Jr EF, Harsah DW 1979 Racial differences of parameters associated with blood pressure levels of childrenThe Bogalusa Heart Study. Metabolism 28:1218-1228

17. Voors AW, Weber LS, Berenson GS 1980 Racial contrasts in cardiovascular response tests for children from a total community. Hypertension 2:686694

18. Voors AW, Dalferes ER, Frank GC, Aristimuno GG, Berenson GS 1983 Relation between ingested potassium and sodium balance in young Blacks and whites. Am J Clin Nutr 37:583-594

19. Lauer RM, Burns TL, Clarke WR 1985 Assessing children's blood pressureconsiderations of age and body size: The Muscatine Study. Pediatrics 75:1081-1090

20. Voors AW, Webber LS, Frerichs RR, Berenson GS 1977 Body height and body mass as determinants of basal blood pressure in children-The Bogalusa Heart Study. Am J Epidemiol 106:101-108

21. Panico S, Celentano E, Krogh V, Jossa F, Farinaro E, Trevisan M, Mancini M 1987 Physical activity and its relationship to blood pressure in school children. J Chronic Dis 40:925-930

22. Hooks PC, Tsong Y, Henske J, Baranowski T, Levin JS. 1986 Social networking as a recruitment strategy for families in community health research.
Hispanic J Behav Sci 8:345-355

23. Hooks PC, Tsong Y, Baranowski T, Henske J, Nader PR, Levin JS. Recruitment strategies for multi-ethnic family and community health research: A primer and model. Community Family Health (in press)

24. Kirkendall WM, Feinleib M, Freis ED, Mark AL 1981 Recommendations for human blood pressure determination by sphygmomanometers. Subcommittee of the AHA Post Graduate Education Committee. Hypertension 3:A510A5 19

25. Curb JD, Labarthe DR, Cooper SP, Cutter GR, Hawkins CM 1983 Training and certification of blood pressure observers. Hypertension 5:620-614

26. Parizkova $\mathbf{J} 1968$ Longitudinal study of the development of body composition and tody build in boys of various physical activity. Hum Biol 40:212-225

27. Dennis B, Ernst N, Hjortland M, Tillotson J, Grambsch V 1980 The NHLBI nutrition data system. J Am Diet Assoc 77:641-645

28. Baranowski T, Dworkin R, Clearman D, Dunn JK, -Nader PR, Hooks PC 1986 The accuracy of children's self reports of diet: Family Health Project. J Am Diet Assoc 86:1381-1385

29. Adams CF 1975 Nutritive Value of American Foods, In Common Units. Agriculture Handbook No. 456. U.S. Department of Agriculture, Agricultural Research Service, Washington, D.C.

30. Pennington JAT, Church HN 1980 Bowes and Church's Food Values of Portions Commonly Used. J.B. Lippincott, Philadelphia

31. Pao, EM, Fleming KH, Guenther PM, Mickle SJ 1982 Foods Commonly Eaten by Individuals: Amount per Daý and per Eating Occasion. Home Economics Research Report Number 44. U.S. Department Agriculture, Human Nutrition Information Service, Consumer Nutrition Center, Hyattsville, $\mathrm{MD}$

32. Sallis JF, Haskell WL, Wood PO, Fortmann SP, Rogers T, Blair SN, Paffenbarger Jr RS 1985 Physical activity assessment methodology in the Five-City Project. Am J Epidemiol 121:91-106

33. Liu K, Dyer AR, Cooper RS, Stamler R, Stamler J 1979 Can overnight urine replace 24-hour urine collection to assess salt intake? Hypertension 1:529536

34. Winer BJ 1971 Statistical Principles in Experimental Design, 2nd ed. McGrawHill, New York

35. Szklo M 1979 Epidemiologic patterns of blood pressure in children. Epidemiol Rev 1:143-169

36. Londe S, Johanson A, Kronemer NS, Goldring D 1975 Blood pressure and puberty. J Pediatr 87:896-900

37. Odeh RE, Fox M 1975 Sample Size Choice. Marcel Dekker, New York 